\title{
ONesc PPGE
}

Criar Educação, Criciúma, v. 8, nำ2, ago/dez 2019.- PPGE - UNESC ISSN 2317-2452

\section{FORMAÇÃO HUMANA EM EXPERIÊNCIAS EDUCATIVAS}

SILVA. Alex Sander da, SILVA e Luzia Batista de Oliveira, (org) Educação, Estética e Experiência: Entre Saberes e Práticas na Contemporaneidade. $1^{\text {a }}$ Ed. São Paulo: Editora Livraria da Física, 2019.

Flávia Moreira Ribeiro ${ }^{1}$ Christian Muleka Mwewa²

Educação, Estética e Experiência: entre saberes e práticas na contemporaneidade, organizado por Alex Sander da Silva e Luzia Batista de Oliveira Silva reúne em nove capítulos análises critico-reflexivas de diferentes autores de distintos campos de experiências e instituições escolares do país, bem como, seus anseios acerca do encargo para a educação.

Em análise inicial é lançado o questionamento a respeito da significação do ato educativo na contemporaneidade. O volume tem como tônica racionalidade formativa refletida nas práticas pedagógicas vigentes e nos fenômenos que se revelam na compreensão social de uma "novidade já vivida", em outros termos, do sempre igual benjaminiano na história da humanidade permeada intencionalmente pelo poderio econômico. Ou seja, do ponto de vista da educação podemos dizer que vivenciamos mais do mesmo (Benjamin, 1994, 1994 e 1995).

Diante da proximidade intelectual, afetiva e teórica, em relação à Walter Benjamin, podemos nos remeter aos ensinamentos adornianos (1995) frente a experiência da educação em sua memória que traz um legado desumanizador, mas próprio do humano, que não se distancia da realidade atual, pois Auschwitz persiste em escala global uma vez que a educação falou. O exemplo mais eloquente da persistência da violência extrema contra o Humano e da falência da educação em termos adornianos é o massacre em Ruanda no início

\footnotetext{
${ }^{1}$ Mestranda em Educação, Universidade Federal de Mato Grosso do Sul, flavinhamorei@gmail.com

${ }^{2}$ Doutor em Ciências da Educação pela Universidade Federal de Santa Catarina (com estágio doutoral na Université Paris 1 - Panthéon Sorbonne). Professor na Universidade Federal de Mato Grosso do Sul (UFMS).E-mail: christian.mwewa@ufms.br
} 
CRIAR EDUCACÃ̃O

\section{unesc PPGE}

Criar Educação, Criciúma, v. 8, no2, ago/dez 2019.- PPGE - UNESC ISSN 2317-2452 dos anos 2000 que matou mais seres humanos em 2 anos do que em toda duração da segunda guerra mundial. Mas, era em Ruanda, no continente africano que muitas vezes é confundido com um 'país'. Quão velhas são as novas estratégias manipuladoras? é preciso uma autoreflexão visando a emancipação humana para que as críticas reverberem em conscientização.

En Indochine, à Madagascar, aux colonies, l'indigène a toujours su qu'il n'y avait rien à attendre de l'autre bord. Le travail du colon est de rendre impossibles jusqu'aux rêves de liberte du colonisé. Le travail du colonisé est d'imaginer toutes les combinaisons éventuelles pour anéantir le colon. (FANON, 2002, p.89).

Os autores do livro em tela referenciam-se criticamente ao princípio civilizatório que se desenvolveu mediante o uso da força e repressão da dignidade humana. Em suas abordagens, a obra elenca características próprias do universo infantil, como por exemplo, destaca a importância da sensibilidade em suas linguagens para a construção do conhecimento em um movimento que respeite as diversidades vivenciadas e experenciadas, pois "criatividade, sentimentos, conhecimentos e memórias que compõem um universo imaginário e real pleno de saberes grandiosos na vida das crianças [ convertem-se em elementos primordiais para a formação]. (SILVA e AGOSTINI, 2019). A experiência formativa traz consigo a necessidade da sensibilidade estética e humanização, a fim de consubstanciar a emancipação e conscientização do bem comum coletivo contrárias ao favorecimento de práticas violentas ou atitudes preconceituosas.

Pode-se dizer que a obra abriga a amplitude das experiências formativas em contextos de diversidades se opondo aos modelos reducionistas e instrumentalizadores. Assim, possibilita o percurso entre passado, presente e futuro para a formação crítica que visa a reflexão na contemporaneidade. A publicação desta obra permite transitar dialeticamente em diferentes culturas nas suas especificidades aportam questões relativas às diversidades no processo formativo.

Dentre as reflexões as experiências realizadas no ensino de filosofia em 


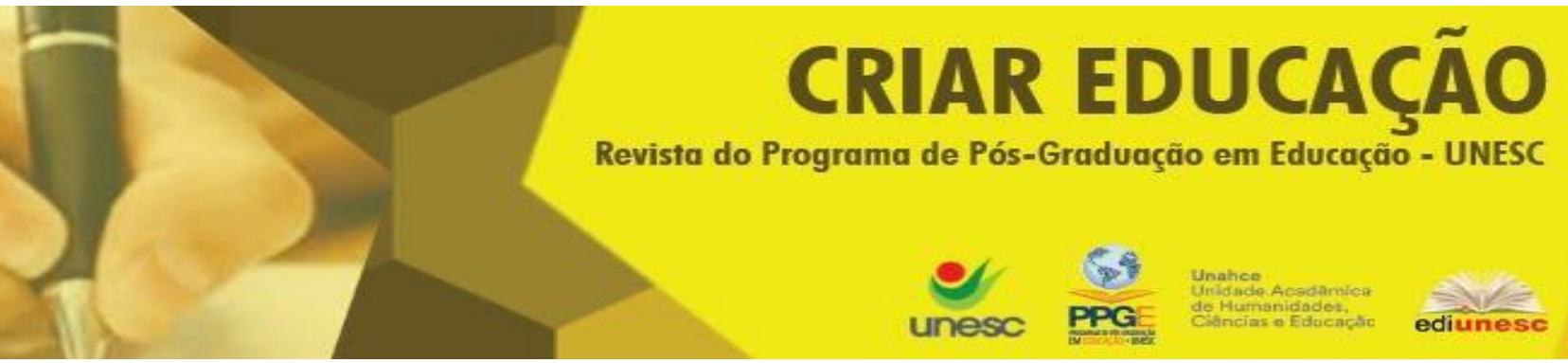

Criar Educação, Criciúma, v. 8, no2, ago/dez 2019.- PPGE - UNESC ISSN 2317-2452 uma escola de Portugal mediante a oferta formativa em nível nacional englobam os desafios enfrentados para uma formação que integre a sociedade de forma humanizante. $O$ autor Celso Carminati relata a observação dos projetos postos em prática que indicam o trato com questões relevantes interculturais e formativas para docentes.

Em face de uma globalização Paulino Eidt e Roque Strieder questionam as relações políticas, econômicas que "diplomaticamente" são representadas pelo muro que aparta México e EUA pela intolerância e a negação do outro por meio de narrativas racistas. Conjecturamos por mudanças, não importa a direção, pois a que temos não nos basta. Essas mudanças no que compete à educação fazem emergir a complexidade envolta das questões étnicas e "raciais" mais uma vez. É preciso discussões nas práticas do cotidiano. Este procedimento reconhece e valoriza as diversidades. Como foi dito em outras ocasiões, é importante tornar a educação antirracista como um norte, pois o racismo epidémico no Brasil esfacela as possibilidades de uma nação entre nós. As relações étnicas, em sala de aula, estruturam outras entre seres humanos aquém dos possuidores dos meios de produção ou força de trabalho. É por isso que importam as lutas pela ética e estética enquanto elementos contra a discriminação nefasta contrária à livre associação (Arendt, 2004). Essas lutas amenizam o sentimento de inexistência dos não-brancos denunciado por Frantz Fanon no clássico Pele negra, mascara branca (1952, p. 112) quando afirma que "sentiment d'infériorité ? Non, sentiment d'inexistence. Le péché est nègre comme la vertu est blanche. Tous ces Blancs réunis, le revolver au poing, ne peuvent pas avoir tort. Je suis coupable. Je ne sais pas de quoi, mais je sens que je suis un misérable."

Quanto às questões que tangem à formação, humanização e sensibilidade, Christian M. Mwewa e Isabela Barbeto discutem a influência do consumismo nas vivências formativas das crianças. Não esquecendo que a chamada literatura infantil é própria do consumismo orquestrado pela indústria cultural (LAJOLO \& ZILBERMAN, 2007 [1985], p. 9-21). No Brasil o reconhecimento da importância da educação infantil, hoje estabelecido em lei 
Criar Educação, Criciúma, v. 8, nำ2, ago/dez 2019.- PPGE - UNESC ISSN 2317-2452 (1996), direciona a finalidade educativa de desenvolvimento integral da criança que compõe inesgotáveis elementos linguísticos. É na escola (instituição) enquanto segunda instância de socialização infantil que a literatura ganha forças normatizadoras e moralizantes, pois na família (primeira instância) a mesma já havia logrado esse engodo.

Mwewa e Barbeto em uma perspectiva lúdica lançam olhares para a literatura infantil uma vez que "a literatura no contexto infantil, como arte, é de extrema importância para o desenvolvimento integral da criança contribuindo para a fantasia e imaginação delas [além do entendimento do mundo em que as crianças estão envolto]" (2019, p. 163, 164). Para tanto, a fantasia,o entendimento e a imaginação, devem ser interpretadas como propulsoras do desenvolvimento cognitivo, emocional, social de qualidade vivencial e experiencial dos sujeitos em contato com a literatura.

Nesse sentido, Mwewa em parceria com Silva ampliam a reflexão acerca da literatura, sobretudo, no que diz respeito à contos afro-brasileiros. Por entender que é na contramão da chamada civilização "europeia" que os contos afro-brasileiros transitam, pois a rua não pode ser apenas de mão única. Aimé Césaire (2010, p. 15) no seu Discurso sobre o colonialismo para afirmar “... a civilização chamada 'europeia', a civilização 'ocidental', tal como foi modelada por dois séculos de regime burguês, é incapaz de resolver os dois principais problemas que sua existência originou: o problema do proletariado e o problema colonial." Portanto, se são problemas criados por Outros podemos sim resolve-los uma vez que Todos estamos envolvidos. Os contos afrobrasileiros vislumbram um caminho de múltiplas mãos. Mas, é bom ficarmos sempre atentos à afirmação de Theodor Adorno (2001) quando diz: "não tenho nenhum preconceito contra os negros, exceto que nada, a não ser a cor [da pele], os distingue dos brancos." (p. 285). Assim é importante ter claro que, "je n'ai pas le droit, moi homme de couleur, de rechercher en quoi ma race est supérieure ou inférieure à une autre race." (FANON, 1952, p. 185).

O livro enfrenta a questão de não apenas refletir sobre a literatura, mas, também indica-la qualificativamente ao nos depararmos com a temática da 
